\title{
Trombose da artéria renal e síndrome do anticorpo antifosfolípide: relato de caso
}

\section{Renal arterial thrombosis and the antiphospholipid antibody syndrome: case report}

\author{
Célia S. Macedo ${ }^{1}$, Roberta S. Martinez ${ }^{2}$, Márcia C. Riyuzo ${ }^{3}$, Herculano D. Bastos ${ }^{4}$
}

\section{Resumo}

Objetivo: descrever um caso clínico raro na infância, com achados clínicos da síndrome do anticorpo antifosfolípide.

Descrição: criança, sexo masculino, com 2 anos e 6 meses de idade, com insuficiência renal, trombose da artéria renal e diagnóstico de síndrome do anticorpo antifosfolípide, foi internada com dor abdominal, palidez, letargia e anúria há 36 horas. Ao exame físico, apresentava-se desnutrida, com hipertensão arterial severa, edema moderado e dor em hipocôndrio. Os achados laboratoriais incluíram: uréia $=112 \mathrm{mg} / \mathrm{dl}$; creatinina plasmática $=4,5 \mathrm{mg} / \mathrm{dl}$; $\mathrm{pH}$ sangüíneo=7,47; bicarbonato sangüíneo=12,8 mmol/L; K=7,2 mEq/L. A diálise peritoneal foi iniciada e mantida por 11 dias. Após 7 semanas de evolução, o paciente ainda necessitava de droga anti-hipertensiva e a função renal estava anormal. A biópsia renal revelou infarto renal anêmico; ultra-sonografia renal com doppler, fluxo sangüíneo renal ausente no lado direito, e a arteriografia mostrou oclusão total da artéria renal direita. A pesquisa de doenças do colágeno foi negativa. Foi realizada nefrectomia à direita obtendo-se normalização da pressão arterial. Aos 5 anos e 8 meses, foi novamente hospitalizada com quadro de crises de ausência e dores abdominais e precordiais. A dosagem do anticorpo anticardiolipina foi positiva. Atualmente aos 7 anos, está em seguimento ambulatorial, assintomática e com dosagens negativas do anticorpo anticardiolipina.

Comentários: as observações deste caso mostram que crianças com quadro de trombose arterial, mesmo na ausência de doenças do colágeno, devem ser investigadas para uma possível associação com a síndrome do anticorpo antifosfolípide.

J Pediatr (Rio J) 2001; 77 (6): 517-21:anticorpos de anticardiolipina, doenças do colágeno, nefrectomia, diálise peritoneal.
1. Prof ${ }^{a}$ Adjunta Livre Docente do Depto. de Pediatria da Faculdade de Medicina de Botucatu- UNESP, disciplina de Nefrologia Pediátrica.

2. Residente de Terceiro Ano em Pediatria do Depto. de Pediatria da Fac. de Medicina de Botucatu - UNESP, área de Nefrologia Pediátrica.

3. Prof $^{\mathrm{a}} \mathrm{Dr}^{\mathrm{a}}$ do Depto. de Pediatria da Faculdade de Medicina de BotucatuUNESP, disciplina de Nefrologia Pediátrica, Doutora em Clínica Médica: área de Nefrologia.

4. Prof. Adjunto Livre Docente do Depto. de Pediatria da Faculdade de Medicina de Botucatu- UNESP, disciplina de Nefrologia Pediátrica. Artigo submetido em 23.01.01, aceito em 13.06.01.

\begin{abstract}
Objective: to describe an unusual case with clinical features of the antiphospholipid syndrome.

Description: white child, two years and six months old, with renal failure, renal arterial thrombosis, and diagnosis of antiphospholipid syndrome was hospitalized with a history of abdominal pain, pallor, lethargy, and anuria for 36 hours. On physical examination, the patient showed malnutrition, high blood pressure, moderate edema, and hypochondrial pain. Laboratory findings included: urea $=112 \mathrm{mg} / \mathrm{dl}$, serum creatinine $=4.5 \mathrm{mg} / \mathrm{dl}$, blood $\mathrm{pH}=$ 7.47, blood bicarbonate $=12.8 \mathrm{mmol} / \mathrm{L}, \mathrm{K}=7.2 \mathrm{mEq} / \mathrm{L}$. Peritoneal dialysis was started and maintained for 11 days. After 7 weeks, the patient still needed anti-hypertensive drugs and the renal function was still abnormal. Renal biopsy was performed and revealed renal infarction. The result of Doppler ultrasonography revealed absent renal blood flow on the right side. Renal arteriography showed total occlusion of the right renal artery. Results for collagen diseases were negative. A right nephrectomy was performed and the blood pressure was controlled. The child was hospitalized again at 5 years and 8 months old with episodes of absence seizures and abdominal and precordial pain. Anticardiolipin antibody test was positive. The child is now 7 years old, asymptomatic, with negative anticardiolipin antibody, and has been under regular follow-up.

Comments: children with arterial thrombosis should be investigated for a possible association with the antiphospholipid antibody syndrome even in the absence of collagen disease.
\end{abstract}

J Pediatr (Rio J) 2001; 77 (6): 517-21: anticardiolipin antibodies, collagen diseases, nephrectomy, peritoneal dialysis.

\section{Introdução}

A trombose da artéria renal é evento pouco comum, que pode estar associado a uma variedade de doenças, como displasia fibromuscular, vasculites, policitemia vera, tumores, trauma, cateterismo da artéria umbelical e com estados hipercoaguláveis, como a síndrome do anticorpo antifosfolípide ${ }^{1}$. 
A síndrome do anticorpo antifosfolípide é caracterizada pela presença de anticorpos com especificidade dirigida para fosfolípides, proteínas plasmáticas ligadas a fosfolípides de cargas negativas ou proteínas plasmáticas isoladas ${ }^{2}$. As manifestações clínicas variam desde quadros subagudos (cefaléia recorrente, distúrbios visuais e disartria ocasional, livedo reticular, tromboses de veias profundas e recorrência de abortos) a graves (insuficiência de valva cardíaca, trombocitopenia e tromboses generalizadas) ${ }^{3}$.

É classificada como primária ou secundária de acordo com a ausência ou presença de conhecido processo de doença reumática de base, respectivamente ${ }^{4}$. Foi inicialmente reconhecida em pacientes com lúpus eritematoso sistêmico, que apresentavam desordem hemorrágica e anticoagulante circulante ${ }^{5}$. Em torno de $50 \%$ de pacientes com lúpus eritematoso sistêmico apresentam o anticorpo antifosfolípide, e metade destes têm morbidade secundária à síndrome do anticorpo antifosfolípide ${ }^{4}$.

Em crianças, existem poucos casos descritos dessa síndrome, sendo a maioria relatos de associações entre a síndrome do anticorpo antifosfolípide e artrite reumatóide juvenil, lúpus eritematoso sistêmico e tromboses ${ }^{6-11}$.

O objetivo deste estudo é relatar um caso de criança com trombose da artéria renal e diagnóstico de síndrome do anticorpo antifosfolípide primária.

\section{Relato de Caso}

Criança de 2 anos e 6 meses, do sexo masculino, natural e procedente de Tatuí -SP, sexto filho de mãe multípara, nascido de parto normal, gestação e puerpério sem intercorrências; apresentava-se bem até a internação na Enfermaria de Pediatria do Hospital da Faculdade de Medicina de Botucatu-UNESP, em 31/07/95.

A criança foi encaminhada ao nosso serviço devido a quadro abrupto de dor abdominal há 12 dias, tendo sido internada em outro serviço e tratada com antibióticos (cefalosporina e aminoglicosídeos) com suspeita de pielonefrite. Apresentava também história de 36 horas de anúria, palidez e apatia. Ao exame físico, apresentava-se em regular estado geral, obnubilada e às vezes irritada, com olhar vago, hipertensa $(\mathrm{PA}=160 / 120 \mathrm{mmHg}), \mathrm{FC}=120 \mathrm{bpm}$ e $\mathrm{FR}=38$ irpm, afebril, edema palpebral $+2 /+4$, palidez cutânea $+2 /+4$ e dor à palpação do hipocôndrio direito; sem demais alterações de outros sistemas. Os exames laboratoriais revelaram leucocitose de 24.600 cél $/ \mathrm{mm}^{3}$, uréia e creatinina séricas de $112 \mathrm{mg} / \mathrm{dl} \mathrm{e} 4,5 \mathrm{mg} / \mathrm{dl}$, respectivamente; $\mathrm{pH}$ sangüíneo $=7,43$, bicarbonato sangüíneo de 12,8 $\mathrm{mmol} / \mathrm{L}$ e potássio sérico de 7,2 $\mathrm{mEq} / \mathrm{L}$. Foi internado em UTI para monitorização do distúrbio metabólico e da hiperpotassemia. Iniciou-se o tratamento dialítico, o qual foi mantido por 11 dias, quando apresentou diurese efetiva $(>1,0 \mathrm{ml} / \mathrm{kg} / \mathrm{h})$. Durante a internação, foram mantidas as medidas de suporte para manutenção de níveis de uréia abaixo de $100 \mathrm{mg} / \mathrm{dl}$ e tratada a hipertensão com a nifedipina.
$\mathrm{Na}$ investigação inicial, o exame de ultra-sonografia renal revelou rins simétricos, contornos regulares, rim direito medindo $6,9 \mathrm{~cm}$ e rim esquerdo medindo $6,7 \mathrm{~cm}$. Exame de fundo de olho com retinopatia hipertensiva A1H1; eletrocardiograma e ecocardiograma com resultados dentro da normalidade para a idade.

Após 7 semanas de internação, o paciente ainda necessitava de tratamento anti-hipertensivo, e não tendo ocorrido ainda a normalização da função renal, o paciente foi submetido à biópsia renal à direita, constatando-se infarto renal anêmico. Diante desse diagnóstico, foi realizada a ultrasonografia renal com doppler que revelou rins assimétricos; o rim direito mediu $4,3 \mathrm{~cm}$ e o esquerdo $6,8 \mathrm{~cm}$, com ausência de fluxo intra-renal à direita. A cintilografia renal com GHA Tc ${ }^{99}$ revelou exclusão funcional do rim direito e comprometimento da perfusão no rim esquerdo (Figura 1). A arteriografia demonstrou a aorta torácica e abdominal normais, artéria renal direita com $100 \%$ de oclusão em terço proximal e artéria renal esquerda sem alterações (Figura 2). A pesquisa imunológica para lúpus eritematoso foi negativa; a velocidade de hemossedimentação e a dosagem de mucoproteína estavam dentro da normalidade; a proteína reativa $\mathrm{C}$ e a prova do látex foram negativas, e o coagulograma foi normal. Foi submetido à nefrectomia à direita $\mathrm{e}$ 


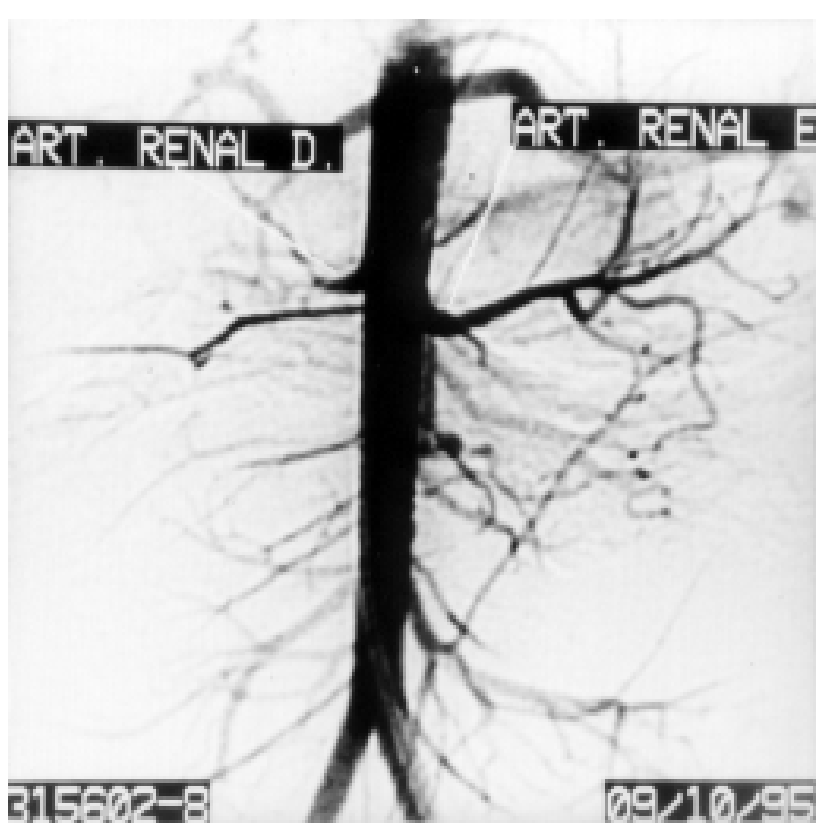

Figura 2 - Arteriografia demonstrando aorta torácica e abdominal normais, artéria renal direita com $100 \%$ de oclusão em terço proximal e artéria renal esquerda sem alterações

evoluiu com melhora da hipertensão arterial. No seguimento ambulatorial, apresentou desenvolvimento e estatura normais, sendo necessária a manutenção de medicação anti-hipertensiva (captopril). O clearance de creatinina 8 meses após a nefrectomia era de $30 \mathrm{ml} / \mathrm{mim} / 1,73 \mathrm{~m}^{2} \mathrm{SC}$.

Aos 5 anos e 8 meses de idade, em uso da mesma medicação, referiu que, há 1 mês, apresentava-se com dor abdominal, dispnéia aos esforços, dor precordial que se irradiava para a face lateral do pescoço à esquerda e sinais de crise de ausência. Ao exame físico, apresentava-se com estado geral preservado, contactuante, peso de $17.900 \mathrm{~kg}$ (percentil 10, tabela NCHS), estatura de $105 \mathrm{~cm}(<$ percentil 5 , tabela NCHS), $\mathrm{PA}=100 / 60 \mathrm{mmHg}, \mathrm{FC}=76 \mathrm{bpm}$ e $\mathrm{FR}=20$ irpm. Pele e mucosas descoradas $+2 /+4$, sopro cardíaco $+2 /+6$. Na avaliação das queixas, o eletrocardiograma e ecocardiograma realizados foram normais, e o sopro cardíaco considerado funcional. O clearance de creatinina era de $50 \mathrm{ml} / \mathrm{mim} / 1,73 \mathrm{~m}^{2} \mathrm{SC}$. A ultra-sonografia renal com doppler revelou ausência do rim direito e perfusão preservada em rim esquerdo, com tamanho de $8,3 \mathrm{~cm}$; o exame de fundo de olho foi normal, sorologia para lúpus eritematoso foi negativa. Durante a internação, diagnosticou-se síndrome convulsiva e o paciente recebeu anticonvulsivante com desaparecimento dos sintomas e tendo tido alta em 3 semanas. No seguimento ambulatorial, foi realizada a pesquisa de anticorpo anticardiolipina, que revelou-se positiva para IgG. Diante do quadro de trombose arterial renal sem causa definida e desse resultado positivo, sugeriu-se como etiologia a síndrome do anticorpo antifosfolípide. Nessa ocasião, a criança não recebeu nenhum tratamento específico por apresentar-se assintomática.

Aos 7 anos, em seguimento ambulatorial, a criança apresentava-se com estado geral preservado, recebendo anti-hipertensivo e anticonvulsivante e com as dosagens de antigoagulante lúpico e anticorpo anticardiolipina negativos (1 ano após o resultado positivo).

\section{Discussão}

A síndrome do anticorpo antifosfolípide é uma desordem trombótica caracterizada pela associação de trombose venosa ou arterial com anticorpos dirigidos contra fosfolípides $^{12}$. Os anticorpos antifosfolípides constituem um grupo heterogêneo de imunoglobulinas que diferem entre si quanto ao isótipo, especificidade antifosfolipídica, características imunoquímicas, ligação a co-fatores protéicos e patogenicidade ${ }^{13}$. Na detecção de anticorpos associados à síndrome do anticorpo antifosfolípide, utiliza-se habitualmente dosagem de anticorpos anticardiolipina e de anticoagulantes lúpicos, sendo estes considerados testes-ouro para o diagnóstico da doença ${ }^{14}$.

Não são conhecidos, completamente, os antígenos envolvidos na produção destes anticorpos; admite-se que estes anticorpos podem ligar-se diretamente a fosfolípides com cargas negativas (fosfatidilserina, ácido fosfatídico, fosfatidiletanolamina e fosfatidilinositol) ou através de cofatores plasmáticos (beta 2-glicoproteína 1, protrombina, proteínas $\mathrm{C}$ e $\mathrm{S})^{13}$.

Durante muitos anos, a idéia prevalente quanto a patogênese dessa síndrome era a de que os anticorpos dirigidos contra fosfolípides da membrana de células do endotélio vascular seriam responsáveis pelos eventos trombóticos ${ }^{15}$. Dados recentes sugerem que esses anticorpos sejam específicos para proteínas plasmáticas, que se ligam a fosfolípides do endotélio, atuando como verdadeiros antígenos, uma vez que a cardiolipina e os fosfolípides, de um modo geral, são pouco antigênicos ${ }^{13}$.

Outros mecanismos implicados na formação de trombos são: maior ativação do endotélio vascular, resultando no aumento da adesão de monócitos e plaquetas ativadas; exacerbação da expressão do fator tecidual na superfície de monócitos, que constitui o principal iniciador da coagulação in vivo; inibição da atividade da proteína $\mathrm{C}$, da proteína $\mathrm{S}$ e de outros fatores da coagulação ${ }^{16,17}$.

Segundo Alargon-Segovia et al. ${ }^{18}$, o diagnóstico da síndrome do anticorpo antifosfolípide primária é feito pela presença de altos títulos do anticorpo antifosfolípide e de duas ou mais manifestações clínicas em um indivíduo com ausência do diagnóstico de doença reumática de base ${ }^{18}$.

Nessa síndrome, as tromboses arteriais podem ocorrer em várias localizações: cerebral ${ }^{17-21}$, retina ${ }^{22}$, coronária $^{23}$, mesentérica $^{24,25}$ e vasos periféricos ${ }^{4,19}$. Trombose das artérias cerebrais é um achado freqüente na criança com a síndrome do anticorpo antifosfolípide ${ }^{5,26-30}$. Por outro 
lado, há poucos relatos da ocorrência de trombose de artéria renal nessa síndrome na criança.

Em 1990, foi descrito um dos primeiros casos da síndrome do anticorpo antifosfolípide associada à trombose da artéria renal em uma menina portadora de lúpus eritematoso sistêmico ${ }^{7}$. Semelhante ao nosso caso, a criança relatada por Ostuni et al. ${ }^{7}$ apresentava quadro de dor abdominal, hipertensão grave, febre, convulsões, oligúria, hematúria microscópica e altos níveis de anticorpo IgG para cardiolipina.

Recentemente, o comprometimento de artérias renais foi descrito em 2 de 5 casos de crianças com hipertensão de origem renovascular e com a síndrome do anticorpo antifosfolípide ${ }^{30}$. Nestas duas crianças, a oclusão da artéria renal abrangia um terço e dois terços da luz, e não apresentaram comprometimento da função renal; diferente do ocorrido em nosso paciente, que apresentou oclusão de $100 \%$ da luz da artéria renal e permaneceu em insuficiência renal.

Embora as manifestações renais da síndrome do anticorpo antifosfolípide tenha recebido escassa atenção até recentemente, o rim, provavelmente, é um dos principais órgãos afetados nessa síndrome. A trombose pode desenvolver-se em qualquer localização dentro dos vasos renais, no tronco ou ramos da artéria renal, arteríolas e artérias intrarenais, capilares glomerulares e veia renal ${ }^{31}$.

As manifestações clínicas do comprometimento renal consistem de graus variáveis de proteinúria, hematúria, hipertensão sistêmica variando de leve à maligna, necrose cortical, microangiopatia trombótica associada ou não à gestação, e falência renal lenta a rapidamente progressi$\mathrm{va}^{31}$.

Infartos renais têm sido descritos na chamada síndrome catastrófica do anticorpo antifosfolípide, caracterizada por múltiplas oclusões vasculares e com conseqüente insuficiência renal e mortalidade de $60 \%{ }^{32}$.

Não há critérios universalmente aceitos para o diagnóstico da síndrome do anticorpo antifosfolípide; também não está totalmente esclarecido se os anticorpos antifosfolípides constituem agentes causais ou são epifenômenos. Na prática clínica, sua detecção constitui o único teste sorológico confiável para o diagnóstico da síndrome do anticorpo antifosfolípide, entretanto a interpretação dos ensaios para a detecção de anticorpos anticardilipina e anticoagulante lúpico ainda não está bem estabelecida. Há dificuldades na interpretação da determinação do ponto de corte positivo, das flutuações de títulos em um mesmo paciente, da discordância de resultados em vários laboratórios e do fato de que muitos pacientes com a síndrome do anticorpo antifosfolípide bem documentada poderem, eventualmente, se tornar soronegativos $^{13,14}$.

Com relação ao tratamento dessa doença, têm sido utilizadas drogas imunossupressoras, antiplaquetárias e anticoagulantes ${ }^{4}$. Em um estudo de 147 pacientes, adolescentes e adultos, o anticoagulante foi utilizado com boa resposta, o que sugere que a anticoagulação parece ser a medida mais eficaz de mudança na história natural da doença $^{33}$. É sugerido o tratamento anticoagulante com heparina na fase aguda e o uso profilático de antiagregantes plaquetários até a negativação do anticorpo anticardiolipina ${ }^{15}$. No presente caso, no momento do diagnóstico da trombose arterial renal, o paciente não tinha o diagnóstico da síndrome do anticorpo antifosfolípide; posteriormente, quando da obtenção da positividade deste anticorpo, o paciente estava assintomático, optando-se por não medicar. Desta forma, realizou-se seguimento com consultas freqüentes e dosagens regulares do anticorpo anticardiolipina.

Diante do exposto, o paciente que relatamos apresenta quadro associado à síndrome do anticorpo antifosfolípide. Trata-se de caso raro em criança, existindo poucos relatos na literatura; os protocolos de tratamento estão sendo ainda definidos, sendo, portanto, necessário o seguimento multidisciplinar e prolongado. Além disso, a síndrome do anticorpo antifosfolípide primária em crianças deve ser incluída no diagnóstico diferencial nos quadros de trombose inexplicada.

\section{Referências bibliográficas}

1. Novick AC. Renal vascular hypertension in children. In: Kelalis PP, King LR, Belman AB, eds. Clinical Pediatric Urology. $2^{\mathrm{a}}$ ed. Philadelphia: WB Saunders; 1985. p.1046-72.

2. Hughes GRV. Thrombosis, abortion, cerebral disease and lupus anticoagulant. BMJ 1983; 287: 1088-91.

3. Hughes GRV. The antiphospholipid syndrome: ten years on. Lancet 1993; 342: 341-4.

4. Lockshin MD. Answers to the antiphospholipid syndrome? N Engl J Med 1995; 32: 1025-7.

5. von Scheven E, Athreya BH, Rose CD, Goldsmith DP, Morton L. Clinical characteristics of antiphospholipid antibody syndrome in children. J Pediatr 1996; 129: 339-45.

6. Shergy WJ, Kredich DW, Pisetsky DS. The relationship of anticardiolipin antibodies to disease manifestations in pediatric systemic lupus erythematosus. J Rheumatol 1988; 15: 1389402.

7. Ostuni PA, Lazzarin P, Pengo V, Ruffatti A, Shiavon F, Gambari P. Renal artery thrombosis and hypertension in a 13 year old. Ann Rheum Dis 1990; 49: 184-87.

8. Caporali R, Ravelli A, de Gennaro F, Neirotti G, Montecucco C, Martini A. Prevalence of anticardiolipin antibodies in juvenile chronic arthritis. Ann Rheum Dis 1991, 50: 599-601.

9. Montes de Oca MA, Babron MC, Blétry O, Broyer M, Courtecuisse V, Fontine JL, et al. Thrombosis in systemic lupus erythematosus: a French collaborative study. Arch Dis Child 1991; 66: 713-7.

10. Seaman DE, Londino AV, Manzi S, Medsger TA. Antiphospholipid antibodies in pediatric systemic lupus erythematosus. Arthritis Rheum 1993; 36 (Suppl 5): R15.

11. Manco-Johnson MJ, Nuss R. Lupus anticoagulant in children with thrombosis. Am J Hematol 1995; 48: 240-3. 
12. Sammaritano LR, Gharavi AE, Lochshin MD. Antiphospholipid antibody syndrome: immunologic and clinical aspects. Semin Arthritis Rheum 1990; 20: 81-96.

13. Roubey RAS. Immunology of the antiphospholipid antibody syndrome. Arthritis Rheum 1996; 39: 1444-54.

14. Piette JC. 1996 diagnostic and classification criteria for the antiphospholipid/cofactors syndrome: a "mission impossible"? Lupus 1996; 5: 354-63.

15. McNeil HP, Chesterman CN, Krillis AS. Immunology and clinical importance of antiphospholipid antibodies. Adv Immunol 1991; 49: 193-280.

16. Simantov R, La Sala JM, Lo SK, Gharavi AE, Samaritano LR, Salmon JE, et al. Activation of cultured vascular endothelial cells by antiphospholipid antibodies. J Clin Invest 1995; 96: 2211-19.

17. Cuadrado MJ, López-Pedrera C, Khamashta MA, Camps MT, Tinahones F, Torres A, et al. Thrombosis in primary antiphospholipid syndrome: a pivotal role for monocyte tissue factor expression. Arthritis Rheum 1997; 40: 834-41.

18. Alarcon-Segovia D, Sanches-Guerrero J. Primary antiphospholipid syndrome. J Rheumatol 1989; 16: 482-8.

19. Carreras LO, Defreyn G, Machin SJ, Vermylen J, Deman R, Spitz B, et al. Arterial thrombosis, intrauterine death and the lupus anticoagulant detection of immunoglobulin interfering with prostacyclin formation. Lancet 1981, 1: 244-6.

20. Harris EN, Gharari AE, Asherson RA, Boey ML, Hughes GRV. Cerebral infarction in systemic lupus: association with anticardiolipin antibodies. Clin Exp Rheumatol 1984; 1: 47-51.

21. Mueh JR, Herbst KD, Rappaport SI. Thrombosis in patients with the lupus anticoagulant. Ann Intern Med 1988; 92: 156-8.

22. Hall S, Buettner H, Harvinder LS. Occlusive retinal vascular disease in systemic lupus erythematosus. J Rheumatol 1984; 11 : 846-50.

23. Hamsten A, Norberg R, Björkholm M, de Faire U, Holm G. Antibodies to cardiolipin in young survivors of myocardial infarction: an association with recurrent cardiovascular events. Lancet 1986, 1: 113-6.

24. Asherson RA, Mackworth-Young CG, Harris EN, Gharari AE, Hughes GRV. Multiple venous and arterial thrombosis associated with the lupus anticoagulant and antibodies to cardiolipin in the absence of SLE. Rheumatol Int 1985; 5: 91-3.
25. Asherson RA, Morgan SH, Harris EN, Gharari AE, Krausz T, Hughes GRV. Arterial occlusion causing large bowel infarction: a reflection os clotting diathesis in SLE. Clin Rheumatol 1986, 1: $102-6$.

26. Kelly R, Berger J. Ischemic stroke in a girl with lupus anticoagulant. Pediatr Neurol 1986; 3: 58-61.

27. Roddy S, Giang D. Anticuerpos antifosfolipido y accidente vascular celebral en un lactante. Pediatrics 1991, 31: 351-3.

28. Sinisi L, Palma V, Mansi D. Antiphospholipid antibodies in young adults with cerebrovascular ischemic disease. Acta Neurol Napoli 1992; 14: 381-6.

29. Olson JS, Konkol RJ, Gill JC, Dobyns WB, Coull BM. Childhood stroke and lupus anticoagulant. Pediatr Neurol 1994; 10: 54-7.

30. Caggiani M, Aldao J, Otero A, Cotic G, Nairac A. Síndrome de anticuerpos antifosfolípidos primarios en el niño. Presentación de cinco casos clínicos. J Pediatr (Rio J); 1999; 75: C23-C30.

31. Piette JC, Cacoub P, Wechsler B. Renal manifestations of the antiphospholipid syndrome. Semin Arthritis Rheum 1994, 23: 357-66.

32. Asherson RA, Piette JC. The catastrophic antiphospholipid syndrome 1996: acute multi-organ failure associated with antiphospholipid antibodies: a review of 31 patients. Lupus 1996; 5: 414-7.

33. Khamashta MA, Cuadrado MJ, Mujic F, Taub NA, Hunt BJ, Hughes GRV. The management of thrombosis in the antiphospholipid-antibodies syndrome. N Engl J Med 1995; 332: 993-7.

Endereço para correspondência:

Dr $^{\mathrm{a}}$ Célia S. Macedo

Depto. de Pediatria da Faculdade de Medicina de Botucatu

UNESP - Rubião Jr. s/n - CEP 18618-970 - Botucatu, SP

Fone/Fax (014) 6802.6274 / 6802.6083

E-mail: pediatri@fmb.unesp.br 